\title{
Blood Lead Levels and Potential Risk Factors for Lead Exposures Among South Asians in New York City
}

\author{
Paromita Hore ${ }^{1}$ (D) Munerah S. Ahmed ${ }^{1} \cdot$ Slavenka Sedlar $^{1} \cdot$ Robert B. Saper $^{2}$ • \\ Deborah Nagin $^{1} \cdot$ Nancy Clark ${ }^{1}$
}

Published online: 25 March 2016

(C) The Author(s) 2016. This article is published with open access at Springerlink.com

\begin{abstract}
New York City's South Asian children and pregnant women have a disproportionate burden of elevated blood lead levels. This study is the first to investigate blood lead levels and risk factors for lead exposures among South Asian New Yorkers. A survey and a finger-stick blood lead test using a portable analyzer were administered to 230 South Asian adults and children. Blood lead levels of $5 \mu \mathrm{g} / \mathrm{dL}$ or higher were found in $20 \%$ of the adults and $15 \%$ of the children, as compared to $5 \%$ of adults and $2.5 \%$ of children citywide. Factors associated with elevated blood lead levels were recent repair work at home, not speaking English, Bangladeshi or Indian ethnicity, and occupational risk factors. Public health professional should be aware that South Asians may be at an increased risk for elevated blood lead levels.
\end{abstract}

Keywords Lead poisoning · South Asian · Ethnic disparities $\cdot$ Risk assessment $\cdot$ Biomonitoring

\section{Background}

Lead poisoning is a preventable public health problem. Adverse health effects of elevated blood lead levels are well-documented [1, 2]. New York City (NYC) witnessed a dramatic decline in lead poisoning. Yet surveillance data

Paromita Hore phore@health.nyc.gov

1 Bureau of Environmental Disease and Injury Prevention, New York City Department of Health and Mental Hygiene, 125 Worth Street, CN34C, New York, NY, USA

2 Boston University School of Medicine, Boston, MA, USA indicates lead poisoning disproportionately affect minority and foreign-born populations, including children and pregnant women from Bangladesh, India, and Pakistan [3, 4].

In 2012, $14 \%$ of NYC children with elevated blood lead levels were foreign-born with almost half born in Bangladesh or Pakistan. Similarly, $93 \%$ of pregnant women with elevated blood lead levels were foreign-born with almost one out of four born in these countries. Surveillance data, however, is restricted to groups that receive routine blood lead testing. Blood lead testing in New York State (NYS) is mandatory for children ages 1 and 2 years and occupationally exposed adults. Older children and pregnant women are tested if providers assess them at risk for lead exposure. Consequently, information on the blood lead levels within South Asian communities is fragmented. In addition, the prevalence of risk factors and associations between these risk factors and blood lead levels is poorly understood.

Multiple factors may explain the increased vulnerability for lead poisoning among the city's Bangladeshi, Indian, and Pakistani communities. Foreign birth or travel abroad may increase risk as environmental lead exposure may be more common in developing countries as compared to the United States (US) [5]. Use of imported products manufactured or obtained in countries where product safety standards may not be stringent can further contribute to their risk [6-8]. The NYC Department of Health and Mental Hygiene (DOHMH) investigated numerous cases of lead poisoning in South Asian children and adults associated with the use of products containing high levels of lead. Examples include: turmeric, chili powder, and other spices obtained in Bangladesh, India, or Pakistan; a variety of Ayurvedic and other traditional medicines both hand-made and manufactured in India; the eye cosmetics kohl, kajal or 
surma which are widely used in South Asia; and sindoor, a red or orange powder used for religious practices in Hinduism [7]. Despite these known vulnerabilities, little information is available about the blood lead levels of many segments of the South Asian population in the US, the prevalence of specific risk factors in these communities, and the association between these risk factors and blood lead levels. DOHMH conducted a study to understand these vulnerabilities by investigating blood lead levels and risk factors for lead exposures within NYC South Asian communities.

\section{Methods}

\section{Study Design}

This cross-sectional study consisted of a risk assessment survey and finger-stick blood lead test administered to a convenience sample of 230 NYC men, women, and children who self-identified as Bangladeshi, Indian, or Pakistani. The DOHMH Institutional Review Board approved the study.

\section{Recruitment and Data Collection}

Recruitment and data collection occurred primarily in NYC's South Asian neighborhoods from August 2008 to December 2009. DOHMH collaborated with two community-based organizations that provide a variety of services to these communities including English classes, support groups, and health education. DOHMH convened multilingual focus groups composed of women recruited by both organizations to review survey questions for clarity and cultural appropriateness, and to identify linguistically correct terms for certain risk factors. Focus group feedback and the community organizations guided recruitment strategies including the identification of screening locations. Community partners notified clients of screenings and distributed flyers prior to an event. In addition, project staff distributed flyers on the days of screening events. Screening locations included community and religious centers, schools, health clinics, and health fairs.

The survey consisted of questions on demographics, medical history, and environmental and behavioral risk factors for lead poisoning. In addition, participants were asked if they or anyone in the household performed certain jobs, hobbies, or activities associated with lead exposure. Bilingual DOHMH staff or, when necessary, trained volunteers administered the survey as a face-to-face interview. Nurses and phlebotomists collected blood samples using a portable ESA Magellan Biosciences CLIA-waived LeadCare II Blood Lead Analyzer with a reportable range from
3.3 to $65 \mu \mathrm{g} / \mathrm{dL}$. Blood lead levels $<3.3 \mu \mathrm{g} / \mathrm{dL}$ and $>65 \mu \mathrm{g} / \mathrm{dL}$ were reported as "low" and "high", respectively. Participants with finger-stick blood lead levels $>8 \mu \mathrm{g} / \mathrm{dL}$ were offered confirmatory venous blood testing per NYS Department of Health requirements. Recommended quality control measures were taken during each screening event to ensure the accuracy of blood sample results.

\section{Statistical Analyses}

Descriptive statistics analyzed socio-demographic characteristics, blood lead levels, and environmental and behavioral risk factors for lead poisoning. Associations were investigated using $t$ tests, univariate regression analyses, and analysis of variance (ANOVA). Multivariate logistic regression modelling identified factors associated with blood lead levels of $5 \mu \mathrm{g} / \mathrm{dL}$ or greater. Environmental and behavioral risk factors were fitted in a multivariate logistic regression model. Age, gender and foreign birth status were a priori included into a separate multivariate logistic regression model together with socio-demographic variables associated with blood lead levels at a significance level of $p<0.20$ in univariate analyses. A multivariate regression model with backward elimination that included these socio-demographic variables and environmental and behavioral variables was also tested. The natural logarithm of blood lead level was used in parametric analyses. Blood lead levels below the reportable range were substituted with the detection limit divided by the square root of two. Analyses were performed using SAS 9.1 and SPSS 19.

\section{Results}

\section{Socio-demographic Characteristics}

Participants were primarily adults (77\%) and females (60\%) (Table 1). The average age was 46.2 years for adults and 7.5 years for children. Most adults were foreignborn (99\%), whereas the majority of the children were born in the US (63\%). Approximately $30 \%$ of participants have been in the US $<5$ years. Of the participants, $40 \%$ identified as Indian, $35 \%$ as Bangladeshi, $24 \%$ as Pakistani, and $1 \%$ as more than one South Asian ethnicity. The most frequent languages spoken among the $44 \%$ who did not speak English were Bengali (34\%), Punjabi (34\%), Urdu (22\%), and Hindi (12\%). Higher education was reported by $47 \%$ of adults. A household income below $\$ 20,000$ was reported by $35 \%$ of participants. Approximately $25 \%$ of participants had no health insurance. 
Table 1 Distribution of blood lead levels by socio-demographic, environmental and behavioral factors

\begin{tabular}{|c|c|c|c|c|c|}
\hline Characteristics & $n(\%)$ & $\begin{array}{l}\text { Geometric mean BLL }(\mathrm{SD})^{\mathrm{a}} \\
(\mu \mathrm{g} / \mathrm{dL})\end{array}$ & $\begin{array}{l}\text { BLL } \\
<5(\mu \mathrm{g} / \mathrm{dL}) \\
n(\%)\end{array}$ & $\begin{array}{l}\text { BLL } \\
5-<10(\mu \mathrm{g} / \mathrm{dL}) \\
n(\%)\end{array}$ & $\begin{array}{l}\text { BLL } \\
\geq 10(\mu \mathrm{g} / \mathrm{dL}) \\
n(\%)\end{array}$ \\
\hline Total & $230(100)$ & $3.3(1.6)$ & $187(81)$ & $34(15)$ & $9(4)$ \\
\hline \multicolumn{6}{|l|}{ Socio-demographic factors } \\
\hline \multicolumn{6}{|l|}{$\operatorname{Age}^{\mathrm{b}}$} \\
\hline Adult & $178(77)$ & $3.3(1.6)$ & $143(80)$ & $26(15)$ & $9(5)$ \\
\hline Children & $52(23)$ & $3.1(1.5)$ & $44(85)$ & $8(15)$ & - \\
\hline \multicolumn{6}{|l|}{ Gender } \\
\hline Female & $139(60)$ & $3.3(1.7)$ & $115(83)$ & $17(12)$ & $7(5)$ \\
\hline Male & $91(40)$ & $3.3(1.6)$ & $72(79)$ & $17(19)$ & $2(2)$ \\
\hline \multicolumn{6}{|l|}{ Country of birth } \\
\hline Foreign-born & $195(85)$ & $3.3(1.6)$ & $157(81)$ & $29(15)$ & $9(5)$ \\
\hline Adults & $176(90)$ & $3.3(1.5)$ & - & - & - \\
\hline Children & $19(10)$ & $3(1.6)$ & - & - & - \\
\hline US-born & $35(15)$ & $3.2(1.5)$ & $30(86)$ & $5(14)$ & $0(0)$ \\
\hline Adults & $2(6)$ & & & & \\
\hline Children & $33(94)$ & & & & \\
\hline \multicolumn{6}{|c|}{ Length of residence in the US (in years) ${ }^{\mathrm{c}, \mathrm{d}}$} \\
\hline$<5$ & $71(31)$ & $3.5(1.5)$ & $55(78)$ & $15(21)$ & $1(1)$ \\
\hline $5-9$ & $64(28)$ & $3.4(1.7)$ & $52(81)$ & $9(14)$ & $3(5)$ \\
\hline 10 or longer & $95(41)$ & $3.1(1.6)$ & $80(84)$ & $10(11)$ & $5(5)$ \\
\hline \multicolumn{6}{|l|}{ Ethnicity $^{\mathrm{c}, \mathrm{e}}$} \\
\hline Bangladeshi & $81(35)$ & $3.6(1.7)$ & $62(77)$ & $14(16)$ & $5(6)$ \\
\hline Indian & $92(40)$ & $3.3(1.6)$ & $73(79)$ & $15(16)$ & $4(4)$ \\
\hline Pakistani & $55(24)$ & $2.9(1.4)$ & $50(91)$ & $5(9)$ & $0(0)$ \\
\hline Other $^{f}$ & $2(1)$ & & - & - & - \\
\hline \multicolumn{6}{|l|}{ English language speaker ${ }^{\mathrm{c}}$} \\
\hline Yes & $129(56)$ & $3.1(1.7)$ & $110(85)$ & $16(12)$ & $3(2)$ \\
\hline No & $101(44)$ & $3.5(1.6)$ & $77(76)$ & $18(18)$ & $6(6)$ \\
\hline \multicolumn{6}{|l|}{ Education (adults) $^{\mathrm{c}}$} \\
\hline Less than high school & 33 (19) & $3.3(1.6)$ & $26(79)$ & $5(15)$ & $2(6)$ \\
\hline High school & $61(34)$ & $3.6(1.8)$ & $47(77)$ & $10(16)$ & $4(7)$ \\
\hline College or more & $84(47)$ & $3.2(1.6)$ & $70(83)$ & $11(13)$ & $3(4)$ \\
\hline \multicolumn{6}{|l|}{ Household income } \\
\hline$<\$ 20,000$ & $80(35)$ & $3.3(1.6)$ & $63(79)$ & $14(18)$ & $3(4)$ \\
\hline$\$ 20,000-<\$ 50,000$ & $64(28)$ & $3.3(1.7)$ & $55(86)$ & $6(9)$ & $3(5)$ \\
\hline$\geq \$ 50,000$ & $23(10)$ & $3.3(1.6)$ & $18(78)$ & $5(22)$ & $0(0)$ \\
\hline Declined/don't know & $63(27)$ & $3.3(1.6)$ & $51(81)$ & $9(14)$ & $3(5)$ \\
\hline \multicolumn{6}{|l|}{ Had health insurance ${ }^{c}$} \\
\hline Yes & $177(77)$ & $3.2(1.6)$ & $149(84)$ & $22(12)$ & $6(3)$ \\
\hline No & $53(23)$ & $3.7(1.7)$ & $38(72)$ & $12(23)$ & $3(6)$ \\
\hline \multicolumn{6}{|c|}{ Environmental and behavioral factors } \\
\hline \multicolumn{6}{|c|}{ Number of risk factors reported } \\
\hline$\geq 1$ risk factor & $224(97)$ & $3.3(1.6)$ & $182(81)$ & $33(15)$ & $9(4)$ \\
\hline No risk factors & $6(3)$ & $2.8(1.4)$ & $5(83)$ & $1(17)$ & $0(0)$ \\
\hline \multicolumn{6}{|l|}{ Repair work at home ${ }^{c}$} \\
\hline Yes & $64(28)$ & $3.9(1.8)$ & $43(67)$ & 17 (27) & $4(6)$ \\
\hline No & $166(72)$ & $3.1(1.5)$ & $144(87)$ & 17 (10) & $5(3)$ \\
\hline
\end{tabular}


Table 1 continued

\begin{tabular}{|c|c|c|c|c|c|}
\hline Characteristics & $n(\%)$ & $\begin{array}{l}\text { Geometric mean BLL }(\mathrm{SD})^{\mathrm{a}} \\
(\mu \mathrm{g} / \mathrm{dL})\end{array}$ & $\begin{array}{l}\text { BLL } \\
<5(\mu \mathrm{g} / \mathrm{dL}) \\
n(\%)\end{array}$ & $\begin{array}{l}\text { BLL } \\
5-<10(\mu \mathrm{g} / \mathrm{dL}) \\
n(\%)\end{array}$ & $\begin{array}{l}\text { BLL } \\
\geq 10(\mu \mathrm{g} / \mathrm{dL}) \\
n(\%)\end{array}$ \\
\hline \multicolumn{6}{|c|}{ Traveled outside of the US ${ }^{c}$} \\
\hline Yes & $115(50)$ & $3.5(1.7)$ & $88(77)$ & $20(17)$ & $7(6)$ \\
\hline No & $115(50)$ & $3.1(1.5)$ & $99(86)$ & $14(12)$ & $2(2)$ \\
\hline \multicolumn{6}{|c|}{ Water damage at home ${ }^{c}$} \\
\hline Yes & $62(27)$ & $3.6(1.8)$ & $48(77)$ & $10(16)$ & $4(6)$ \\
\hline No & $168(73)$ & $3.2(1.6)$ & $139(83)$ & $24(14)$ & $5(3)$ \\
\hline \multicolumn{6}{|c|}{ Occupational risks } \\
\hline Yes & $45(20)$ & $3.6(1.6)$ & $32(71)$ & $11(24)$ & $2(4)$ \\
\hline No & $185(80)$ & $3.2(1.6)$ & $155(84)$ & $23(12)$ & $7(4)$ \\
\hline \multicolumn{6}{|c|}{ History of fractured bones } \\
\hline Yes & $11(5)$ & $3.0(1.6)$ & $9(82)$ & $2(18)$ & $0(0)$ \\
\hline No & $219(95)$ & $3.3(1.6)$ & $178(81)$ & $32(15)$ & $9(4)$ \\
\hline \multicolumn{6}{|c|}{ Had Pica (ingested non-food items) } \\
\hline Yes & $26(11)$ & $3.3(1.6)$ & $22(85)$ & $4(15)$ & $0(0)$ \\
\hline No & $204(89)$ & $3.3(1.6)$ & $165(81)$ & $30(15)$ & $9(4)$ \\
\hline \multicolumn{6}{|c|}{ Used imported ceramic ware ${ }^{c}$} \\
\hline Yes & $9(4)$ & $4.3(1.7)$ & $5(56)$ & $4(44)$ & $0(0)$ \\
\hline No & $221(96)$ & $3.3(1.6)$ & $182(82)$ & $30(14)$ & $9(4)$ \\
\hline \multicolumn{6}{|c|}{ Used imported medicine products } \\
\hline Yes & $29(13)$ & $3.3(1.5)$ & $25(86)$ & $4(14)$ & $0(0)$ \\
\hline No & $201(87)$ & $3.3(1.6)$ & $162(81)$ & $30(15)$ & $9(4)$ \\
\hline \multicolumn{6}{|c|}{ Used imported spices } \\
\hline Yes & $198(86)$ & $3.3(1.6)$ & $163(82)$ & $26(13)$ & $9(5)$ \\
\hline No & $32(14)$ & $3.1(1.5)$ & $24(75)$ & $8(25)$ & $0(0)$ \\
\hline \multicolumn{6}{|c|}{ Used imported cosmetics } \\
\hline Yes & $22(10)$ & $3.3(1.7)$ & $19(86)$ & $1(5)$ & $2(9)$ \\
\hline No & $208(90)$ & $3.3(1.6)$ & $168(81)$ & $33(16)$ & $7(3)$ \\
\hline
\end{tabular}

${ }^{a}$ Log transformed finger-stick blood lead levels were used in all analyses

b Mean age for adults was 46.2 years $(\mathrm{SD}=16.4)$, and for children $<18$ years mean was 7.5 years $(\mathrm{SD}=4.8)$

c This variable was found significant in univariate analyses and included in multivariate logistic regression models

${ }^{\mathrm{d}}$ Mean length of residence in the US was 10.5 years $(\mathrm{SD}=9.6)$

e Post-hoc comparisons showed that the only significant difference in geometric mean blood lead level was between Pakistani and Bangladeshi

${ }^{\mathrm{f}}$ Participants reported more than one South Asian ethnicity. The descriptive statistics were not calculated due to a small $\mathrm{n}$. The two participants were excluded from multivariate logistic regression analyses

\section{Blood Lead Levels}

Blood lead levels ranged from $<3.3$ to $29 \mu \mathrm{g} / \mathrm{dL}$. The eight confirmatory venous blood samples were all within $\pm 4 \mu \mathrm{g} /$ $\mathrm{dL}$ of the corresponding finger-stick levels. Blood lead levels at or above $5 \mu \mathrm{g} / \mathrm{dL}$, indicating elevated lead exposure, were found in $20 \%$ of adults and $15 \%$ of children (Table 1). Approximately $5 \%$ of adults had levels of $10 \mu \mathrm{g} / \mathrm{dL}$ or greater, defined as lead poisoning by the NYC Health Code.

\section{Socio-demographic, Environmental, and Behavioral Risk Factors}

In univariate analyses higher blood lead levels were associated with having no health insurance, not being an English speaker, having recent repair work or water damage at home, recently traveling abroad, ethnicity, education, use of imported ceramicware and length of residence in the US (Table 1). In a multivariate logistic regression model predicting blood lead levels of $5 \mu \mathrm{g} / \mathrm{dL}$ or greater, age, gender, 
foreign birth were included a priori, with other socio-demographic variables that were associated with blood lead levels in univariate analyses (ethnicity, language, health insurance status, education, and length of residence in the US). Only ethnicity remained a significant predictor of elevated blood lead levels. Bangladeshi participants were significantly more likely to have elevated blood lead levels than Pakistani participants (adjusted OR 3.58; $95 \%$ CI 1.20-11.01) (Table 2). In a separate logistic regression model adjusted for all environmental and behavioral risk factors, recent repair work at home significantly increased the odds of having elevated blood lead levels (adjusted OR 3.22 ; $95 \%$ CI 1.49-6.97) (Table 3). The observed effects of ethnicity and repair work at home remained statistically significant in a logistic regression model adjusted for the socio-demographic, environmental, and behavioral risk factors described above (Table 4). Logistic regression modelling with backward elimination resulted in four significant factors that increased odds of having elevated blood lead levels: recent repair work done at home (adjusted OR 4.54; $95 \%$ CI 2.09-9.89); being of Bangladeshi (adjusted OR 5.19; $95 \%$ CI 1.62-16.64) or Indian ethnicity (adjusted OR 4.90; $95 \%$ CI 1.52-15.83); having had occupational risks (adjusted OR 2.69; $95 \%$ CI 1.15-6.30); and being a non-English speaker (adjusted OR 2.27; $95 \%$ CI 1.08-4.77) (Table 5). These factors remained significant when age, gender, and foreign birth were added to the model.

\section{Discussion}

The study is the first, to our knowledge, to examine blood lead levels and potential risk factors within NYC's South Asian communities and to include adults with and without

Table 2 Multivariate logistic regression analyses (socio-demographic variables)

\begin{tabular}{ll}
\hline Variables in the model & Adj. odds ratio $(95 \%$ CI $)$ \\
\hline Ethnicity (Bangladeshi) $^{\mathrm{a}}$ & $3.58(1.20,11.01)^{*}$ \\
Ethnicity (Indian) $^{\mathrm{a}}$ & $3.01(0.95,9.48)$ \\
Non-English language speaker $^{\text {No Health Insurance }}$ & $1.66(0.80,3.47)$ \\
Gender $^{\mathrm{b}}$ & $1.69(0.75,3.77)$ \\
Education (High school) $^{\mathrm{c}}$ & $1.53(0.74,3.19)$ \\
Foreign born $^{\text {Age (in years) }}$ & $1.51(0.58,3.94)$ \\
Length of residence in the US (in years) $^{\mathrm{c}}$ & $0.99(0.95,1.04)$ \\
Education (College) & $1.57(0.38,6.41)$ \\
\end{tabular}

$* p<0.05$

a Reference group is 'Pakistani'

b Reference group is 'Female'

c Reference group is 'Less than high school'
Table 3 Multivariate logistic regression analyses (behavioral and environmental variables)

\begin{tabular}{ll}
\hline Variables in the model & Adj. odds ratio $(95 \% \mathrm{CI})$ \\
\hline Repair work at home $^{\mathrm{a}}$ & $3.22(1.49,6.97)^{* *}$ \\
Traveled outside the US $^{\mathrm{a}}$ & $1.67(0.79,3.52)$ \\
Used herbal medicine products $^{\mathrm{a}}$ & $0.54(0.20,1.46)$ \\
Occupational risks $^{\mathrm{a}}$ & $1.65(0.71,3.83)$ \\
Used glazed dishes $^{\mathrm{a}}$ & $2.11(0.46,9.64)$ \\
Pica $^{\mathrm{a}}$ & $0.57(0.17,1.88)$ \\
Used imported spices $^{\mathrm{a}}$ & $0.68(0.26,1.80)$ \\
Used imported cosmetics $^{\mathrm{a}}$ & $0.71(0.19,2.67)$ \\
History of broken bones & $0.75(0.13,4.14)$ \\
Water damage at home & $\mathrm{a}$
\end{tabular}

$* * p<0.01$

a Reference group are those responding 'No' to a question about presence of a risk factor

Table 4 Multivariate logistic regression analyses (full model)

\begin{tabular}{|c|c|}
\hline Variables in the model & Adj. odds ratio $(95 \% \mathrm{CI})$ \\
\hline Repair work at home $^{\mathrm{a}}$ & $4.40(1.80,10.75)^{* *}$ \\
\hline Ethnicity (Bangladeshi) ${ }^{\mathrm{b}}$ & $5.28(1.44,19.41)^{*}$ \\
\hline Ethnicity (Indian) ${ }^{\mathrm{b}}$ & $4.67(1.31,16.64)^{*}$ \\
\hline Non-English language speaker & $2.03(0.89,4.61)$ \\
\hline Used imported spices ${ }^{\mathrm{a}}$ & $0.51(0.17,1.46)$ \\
\hline Used herbal medicine products ${ }^{\mathrm{a}}$ & $0.50(0.17,1.47)$ \\
\hline No Health Insurance & $1.69(0.68,4.22)$ \\
\hline Occupational risks $^{\mathrm{a}}$ & $1.74(0.66,4.61)$ \\
\hline Traveled outside the US ${ }^{\mathrm{a}}$ & $1.59(0.69,3.64)$ \\
\hline Used glazed dishes ${ }^{\mathrm{a}}$ & $2.27(0.41,12.72)$ \\
\hline Education $\left(\right.$ High school) ${ }^{\mathrm{c}}$ & $1.57(0.54,4.62)$ \\
\hline $\mathrm{Pica}^{\mathrm{a}}$ & $0.61(0.15,2.44)$ \\
\hline Gender $^{\mathrm{d}}$ & $1.33(0.58,3.09)$ \\
\hline Education $(\text { College })^{\mathrm{c}}$ & $0.73(0.24,2.25)$ \\
\hline Foreign Born & $1.53(0.32,7.23)$ \\
\hline Water damage at home ${ }^{\mathrm{a}}$ & $1.23(0.47,3.22)$ \\
\hline Age (in years) & $1.00(0.97,1.03)$ \\
\hline Used imported cosmetics ${ }^{\mathrm{a}}$ & $1.11(0.26,4.71)$ \\
\hline Length of residence in the US (in years) & $1.00(0.95,1.06)$ \\
\hline History of broken bones ${ }^{\mathrm{a}}$ & $0.90(0.15,5.31)$ \\
\hline \multicolumn{2}{|l|}{$* p<0.05 ; * * p<0.01$} \\
\hline \multicolumn{2}{|c|}{$\begin{array}{l}\text { a Reference group are those responding 'No' to a question about } \\
\text { presence of a risk factor }\end{array}$} \\
\hline \multicolumn{2}{|l|}{ b Reference group is 'Pakistani' } \\
\hline \multicolumn{2}{|l|}{ ' Reference group is 'Less than high school' } \\
\hline d Reference group is 'Female' & \\
\hline
\end{tabular}

occupational exposures, non-pregnant and pregnant women, and younger and older children. Understanding lead exposure risks among these communities is necessary to address and reduce disparities in blood lead levels. 
Table 5 Multivariate logistic regression analyses with backward elimination

\begin{tabular}{ll}
\hline Variables in the model & Adj. odds ratio $(95 \% \mathrm{CI})$ \\
\hline Repair work at home $^{\mathrm{a}}$ & $4.54(2.09,9.89)^{* * *}$ \\
Ethnicity (Bangladeshi) $^{\mathrm{b}}$ & $5.19(1.62,16.64)^{* *}$ \\
Ethnicity (Indian) $^{\mathrm{b}}$ & $4.90(1.52,15.83)^{* *}$ \\
Occupational risks $^{\mathrm{a}}$ & $2.69(1.15,6.30)^{*}$ \\
Non-English language speaker & $2.27(1.08,4.77)^{*}$ \\
\hline$* p<0.05 ; * * p<0.01 ; * * * p<0.001$ & \\
${ }^{\mathrm{a}}$ Reference group are those responding 'No' to a question about \\
presence of a risk factor \\
${ }^{\mathrm{b}}$ Reference group is 'Pakistani'
\end{tabular}

One of our main findings was the higher risk for elevated blood lead levels in this cohort. This study not only presented an indication of the blood lead levels within this at-risk group, it also helped identify individuals with elevated blood lead levels that may not have been otherwise captured. Blood lead levels of $10 \mu \mathrm{g} / \mathrm{dL}$ or greater were found in $5 \%$ of adult participants. This was considerably higher than findings from the 2004 NYC Health and Nutrition Examination Survey (CHANES) which estimated $0.5 \%$ of the city's adult population to have such levels [9]. Elevated blood lead levels of $5 \mu \mathrm{g} / \mathrm{dL}$ or greater were found in $20 \%$ of adult participants-four times higher than the CHANES findings. Similarly, $15 \%$ of child participants had blood lead levels of $5 \mu \mathrm{g} / \mathrm{dL}$ or higher compared to $2.5 \%$ estimated among all NYC children [4].

Recent repair work at home and occupational risk factors were significantly associated with blood lead levels. The health impact of work that disturbs lead-based paint is well documented [10, 11]. Implementing safe work practices is necessary for minimizing lead exposures for both residents and workers. Engaging in occupations or hobbies with lead exposure risks such as construction, bridge/steel work, target shooting, or metal or battery recycling was reported by $20 \%$ of participants. Almost $30 \%$ of participants who reported occupational risks had blood lead levels of $5 \mu \mathrm{g} / \mathrm{dL}$ or higher. Interestingly, Punjabi was the most frequent language spoken by participants reporting occupational risk factors suggesting Punjabi speakers may be at higher risk for occupational lead exposure. This also suggests prevalence of certain risk factors varies within subgroups of the city's South Asian communities.

Differences in blood lead levels between ethnicities further indicate that South Asian communities are not uniformly at risk. Bangladeshi or Indian participants had significantly higher blood lead levels compared to Pakistani participants; however, we cannot draw conclusions as to reasons for these differences. Significantly increased odds of having elevated blood lead levels were also found among non-English speakers who are more likely to be foreign-born [12] with higher blood lead levels probably due to both recent and past exposures [13].

Among other risk factors associated with blood lead levels was lack of health insurance. Approximately $30 \%$ of participants without health insurance had blood lead levels $5 \mu \mathrm{g} / \mathrm{dL}$ or higher. Individuals without insurance may delay or forego accessing health care services and have poorer health outcomes [14-18]. Minority and lowincome communities may not only be disproportionally exposed to environmental contaminants but also fare worse to such exposures due, in part, to difficulties in accessing health care $[19,20]$. Having health insurance may serve as a protective factor in another way. Focus group members reported a preference for using allopathic medicines because they are covered by health insurance as opposed to Ayurvedic medications and supplements, some of which have been found to contain high levels of lead $[6,7]$.

Recent travel outside the US was also associated with higher blood lead levels. Unsurprisingly, Bangladesh, India, and Pakistan were the most frequently visited countries. The ease of modern travel has led to an increase of transnational communities-communities of migrants that often live in two countries, the country of migration and the ancestral country [21]. Migrants may spend prolonged periods in developing countries where exposures to higher levels of environmental lead are likely [22, 23]. Travel also increases access to less regulated consumer products which may contain high levels of lead. Users may obtain these contaminated products overseas, either through self-purchase while travelling or from relatives, friends, or providers who live abroad. Access to global markets due to rapid transport options allows such products to also be available for purchase in US markets or online $[24,25]$.

In this study, there were factors which may have contributed to the observed prevalence seen for certain risk factors. For example, only $13 \%$ of participants reported using non-allopathic medicines although such products are widely used in South Asia [26]. Several factors may have contributed to this difference. The study involved a convenience sample of South Asians residing in NYC. South Asian immigrants are likely to differ from those living in South Asia given the very nature of the immigrant experience. In addition, in many South Asian countries access to healthcare is limited because of costs and geography. This may not be the case in NYC as affordable healthcare is more readily accessed. As mentioned above, participants in our focus groups expressed preference for using allopathic medicines because they are covered by health insurance which may explain such low prevalence of use. In addition, some participants may have been reluctant to disclose use of such products during the survey. This 
reluctance was seen among participants using imported medicine products. More than half of the users reported not discussing their use with a medical provider. The main reasons for not discussing use were: "It was not important for the provider to know", "The provider never asked about it" and "The provider would not understand or approve."

While DOHMH continues to identify lead poisoning cases associated with use of consumer products such as imported spices, cosmetics, and medicines or remedies among NYC's South Asians [7], in this study a significant association was not observed between use of such products and blood lead levels. Several limitations may have contributed to the lack of significance for these and other risk factors. A small sample size may have limited the power to detect significant associations. Another limitation was the instrument detection limit of $3.3 \mu \mathrm{g} / \mathrm{dL}$, which was considerably higher than the geometric mean blood lead level of $1.79 \mu \mathrm{g} / \mathrm{dL}$ estimated by CHANES [9]. The imputation method used in this study for values below the detection limit, while common, may have over- or underestimated the mean blood lead levels.

Despite these limitations, the study had several strengths. One strength was the unique approach and flexibility provided by the sampling design. The portable diagnostic device and conducting screenings in familiar and convenient facilities during business and non-business hours encouraged recruitment. Staff members knowledgeable with participants' cultures and languages were able to effectively probe for specific information during interviews. Partnerships with trusted and respected community organizations greatly fostered support for and participation in this study. These organizations continue to serve as conduits in the dissemination of health prevention messages.

Our approach can easily be adapted to other vulnerable populations to investigate potential lead exposure risks, develop interventions, and disseminate health messages. Such an approach can identify subsets of a population with increased vulnerabilities. For example, our study showed that non-English speakers were at a significantly higher risk for elevated blood lead levels. Approximately one out of four non-English speakers had blood lead levels of $5 \mu \mathrm{g} /$ $\mathrm{dL}$ or higher. Languages spoken by these participants were Bengali, Hindi, Urdu, and Punjabi. Punjabi was a language for which DOHMH previously did not have educational materials. Consequently, outreach materials were translated into Punjabi to supplement existing DOHMH literature. These materials continue to be disseminated by DOHMH and partner organizations. Language is a critical component of risk communication for developing effective public health interventions. These findings can help guide risk assessment and the development of lead poisoning prevention strategies for at-risk populations.

\section{Conclusions}

Study findings clearly suggest South Asians are at an increased risk for lead exposure as $20 \%$ of adults-four times the CHANES finding, and $15 \%$ of children compared to $2.5 \%$ estimated among all NYC children, had a blood lead level of $5 \mu \mathrm{g} / \mathrm{dL}$ or higher. Factors including recent repair work at home, not speaking English, Bangladeshi or Indian ethnicity, and occupational risks were significantly associated with elevated blood lead levels. Public health professionals, medical providers, and community organizations should be aware that South Asians may be at an increased risk for elevated blood lead levels and should screen South Asians particularly those with these risk factors. To reduce the disparity in lead exposures between South Asians and the general population, greater efforts to identify, remove, and raise awareness about lead hazards common in these communities are needed.

Acknowledgments The authors thank the study participants and community organizations for their time and dedication: Arab-American Family Support Center, Council of Peoples Organization, East Coast Durga Puja Association, Sikh Cultural Society, Hindu Temple Society of North America, Morris Heights Health Center, Muslim Center of New York, New York Taxi Workers Alliance, Pragati, and South Asian Council for Social Services. The authors also thank the DOHMH Public Health Laboratory for conducting venous blood lead testing. Finally, the authors thank the DOHMH interns, nurses, phlebotomists, researchers and physicians for their contribution to the study.

Funding This study was funded by the Environmental Protection Agency (Grant No. X8-97253308).

\section{Compliance with Ethical Standards}

Conflict of interest All authors declare that they have no conflict of interest.

Ethical Approval This study was approved by the DOHMH Institutional Review Board and is therefore in accordance with the ethical standards of the institutional and/or national research committee and with the 1964 Helsinki declaration and its later amendments.

Informed Consent Informed consent was obtained from all participants included in the study. In the case of minors parental informed consent was obtained. In addition, assent was obtained from children between the ages of 7 and 18 years.

Open Access This article is distributed under the terms of the Creative Commons Attribution 4.0 International License (http://crea tivecommons.org/licenses/by/4.0/), which permits unrestricted use, distribution, and reproduction in any medium, provided you give 
appropriate credit to the original author(s) and the source, provide a link to the Creative Commons license, and indicate if changes were made.

\section{References}

1. Kosnett MJ, Wedeen RP, Rothenberg SJ, et al. Recommendations for medical management of adult lead exposure. Environ Health Perspect. 2007;115(3):463-71.

2. Centers for Disease Control and Prevention: Low level lead exposure harms children: a renewed call for primary prevention. US Department of Health and Human Services, Atlanta, GA. 2012a. http://www.cdc.gov/nceh/lead/acclpp/final_document_ 030712.pdf. Accessed 03 Aug 2015.

3. NYC DOHMH: Preventing Lead Poisoning in New York City. New York, NY, 2007. http://www.nyc.gov/html/doh/downloads/ pdf/lead/lead-2007report.pdf. Accessed 03 Aug 2015.

4. NYC DOHMH: Lead Poisoning in New York City: Continued Decline in 2012. New York, NY, 2014. http://www.nyc.gov/html/ doh/downloads/pdf/lead/lead-2012report.pdf. Accessed 03 Aug 2015.

5. Tehranifar PLJ, Auchincloss AH, Faciano A, et al. Immigration and risk of childhood lead poisoning: findings from a case-control study of New York City children. Am J Public Health. 2008;98(1):92-7.

6. Centers for Disease Control and Prevention. Lead poisoning in pregnant women who used Ayurvedic medications from IndiaNew York City, 2011-2012. MMWR Morb Mortal Wkly Rep. 2012;61(33):641-6.

7. Hore $\mathrm{P}$, Ahmed $\mathrm{M}$, Nagin $\mathrm{D}$, et al. Intervention model for contaminated consumer products: a multifaceted tool for protecting public health. Am J Public Health. 2014;104(8):1377-83.

8. Lin CG, Schaider LA, Brabander DJ, et al. Pediatric lead exposure from imported Indian spices and cultural powders. Pediatrics. 2010;125(4):e828-35.

9. McKelvey W, Gwynn RC, Jeffery N, et al. A biomonitoring study of lead, cadmium, and mercury in the blood of New York City adults. Environ Health Perspect. 2007;115(10):1435-41.

10. Centers for Disease Control and Prevention. Children with elevated blood lead levels attributed to home renovation and remodeling activities-New York, 1993-1994. MMWR Morb Mortal Wkly Rep. 1997;45(51-52):1120-3.

11. Reissman DB, Matte TD, Gurnitz KL, et al. Is home renovation or repair a risk factor for exposure to lead among children residing in New York City? J Urban Health. 2002;79(4):502-11.
12. Grieco E. English abilities of the US foreign-born population. 2003. http://www.migrationpolicy.org/print/4887. Accessed 11 Mar 2015.

13. ATSDR (Agency for Toxic Substances and Disease Registry). Toxicological profile for lead. Atlanta: US Department of Health and Human Services, Public Health Service; 2007.

14. Braveman P, Oliva G, Miller MG, et al. Adverse outcomes and lack of health insurance among newborns in an eight-county area of California, 1982 to 1986. N Engl J Med. 1989;321(8):508-13.

15. Centers for Disease Control and Prevention. Vital signs: health insurance coverage and health care utilization-United States, 2006-2009 and January-March 2010. MMWR Morb Mortal Wkly Rep. 2010;59(44):1448-54.

16. Institute of Medicine. Care without coverage: too little, too late. Washington: National Academy Press; 2002.

17. Institute of Medicine. America's uninsured crisis: consequences for health and health care. Washington: National Academy Press; 2009.

18. McWilliams JM, Meara E, Zaslavsky AM, et al. Health of previously uninsured adults after acquiring Medicare coverage. JAMA. 2007;298(24):2886-94.

19. Carter-Pokras O, Zambrana RE, Poppell CF, et al. The environmental health of Latino children. J Pediatr Health Care. 2007;21(5):307-14.

20. Institute of Medicine: In toward environmental justice, research, education, and health policy needs. Washington, 1999.

21. Handley MA, Grieshop J. Globalized migration and transnational epidemiology. Int J Epidemiol. 2007;36(6):1205-6.

22. Tong S, von Schirnding YE, Prapamontol T. Environmental lead exposure: a public health problem of global dimensions. Bull World Health Organ. 2000;78(9):1068-77.

23. Kirchgatterer A, Rammer M, Knoflach P. Weight loss, abdominal pain and anemia after a holiday abroad-case report of lead poisoning. Dtsch Med Wochenschr. 2005;130(40):2253-6.

24. Saper RB, Kales SN, Paquin J, et al. Heavy metal content of Ayurvedic herbal medicine products. JAMA. 2004;292(23): 2868-73.

25. Saper RB, Phillips RS, Sehgal A, et al. Lead, mercury, and arsenic in US- and Indian-manufactured Ayurvedic medicines sold via the Internet. JAMA. 2008;300(8):915-23.

26. Gogtay NJ, Bhatt HA, Dalvi SS, Kshirsagar NA. The use and safety of non-allopathic Indian medicines. Drug Saf. 2002;25(14):1005-19. 